\title{
On the interaction of P-stranding and Sluicing in Bulgarian
}

\section{Introduction}

This paper is about the grammar of ellipsis, specifically, sluicing (Ross 1969). Sluicing is the process deriving incomplete wh-questions where only the whphrase is pronounced, (1).

(1) a. John bought a car, but I don't know which one.

b. Nino talked with Andrea, but I don't know with who else.

c. A: Hans left. - B: When?

I will suggest that the interaction between preposition stranding, case morphology, and sluicing in the Bulgarian of - at least - some speakers strongly supports an account of sluicing under which (a) the intuitively missing part of the question is syntactically represented, (b) the missing part of the sentence is elided under semantic rather than syntactic identity with the antecedent, and (c) the pronounced wh-phrase has to fit in a specific sense to be discussed into the antecedent. Assumptions (a) and (b) constitute Merchant's (1999, 2001) approach to sluicing. As pointed out by Lasnik (2001, 2005), (a) and (b) by themselves do not derive important, well-established, central properties of sluicing. Assumption (c) is intended to fix this gap in Merchant's account. The conjunction of (a), (b), and (c) makes novel predictions not shared by competing accounts of sluicing like a Lasnik-style syntactic identity account or a Culicover-and-Jackendoff-style account with no syntax at the ellipsis site. The Bulgarian data presented here show

\footnotetext{
Note: I dedicate this paper in gratitude to Gerhild Zybatow. You took me under your wing when I had just finished my Ph.D. and gave me the space to follow my instincts as a postdoc in your project on the information structure of non-declarative clauses in Russian. The papers I wrote were about exclamatives in English and German. They had little to do with information structure and didn't mention Russian. Here, then, is another contribution to the same project. Thank you Gerhild! This paper would not have been possible without the observations gathered by Andriana Koumbarou and Dagmara Grabska on Bulgarian sluicing during my 2014 ACTL course. I also benefited from comments by the audiences at a colloquium talk in Newcastle in 2015, at CECIL'S 5 , and at the 2015 LAGB meeting.
} 
that the specific expectations of the present account are borne out, giving it the empirical edge over its competitors.

It will be useful to settle some terminology before proceeding.

[John bought $\left[\begin{array}{cc}\text { a car }]] \\ \text { [correlate] }\end{array}\right.$
but I don't know
$\left[\begin{array}{c}\text { antecedent }] \\ \text { [ }\end{array}\right]$

I will refer to which one as the remnant. The clause intuitively providing the meaning of the elliptical question, here John bought a car, will be called the antecedent. The indefinite, a car, whose identity is queried in sluicing will be called the correlate. The gap immediately following the remnant, where the remainder of the question would come in a canonical wh-question, will be called the ellipsis site, and the clausal structure containing remnant and ellipsis site form the sluice. ${ }^{1}$ Example (2) has an indefinite correlate whose identity is queried by the sluice. This type of example is called the "merger type" in Chung, Ladusaw, and McCloskey (1995). When there is no overt correlate in the antecedent, we speak of sprouting, (1c). When the correlate is definite and the identity of a different referent satisfying the antecedent is queried, we speak of contrast sluicing, (1b). Finally, when discussing theories of sluicing that assume the presence of unpronounced syntactic structure at the ellipsis site, I will borrow the term "pre-sluice" from Dayal, and Schwarzschild (2010) to refer to the fully pronounced version of the sentence that gives rise to the sluice. A range of plausible pre-sluices for (2) is given in (3).

\section{(3) a. which car he bought \\ b. which car it is}

The question of how ellipsis works has implications far beyond descriptive adequacy. These implications justify the surge of interest in ellipsis in recent years. The central concern of cognitive science is the correct characterization of the initial and final states of a given information processing device, the characterization of the mapping between the two states, and of the extent to which this mapping is modulated by data from the organism's environment. In linguistics, poverty of the stimulus arguments have played a major role in this investigation. Poverty of

1 The distinction between remnant and sluice is important even under theories where there is no syntactic representation of the ellipsis site, because the category of the sluice and the category of the remnant do not match. This fact will be discussed below. 
the stimulus arguments purport to reveal properties of the final state that cannot plausibly be derived from environmental input by general purpose reasoning or pattern extraction devices and that must, therefore, be attributed to the initial state or to specific biases in the mapping. For recent discussion see Pullum, and Scholz (2002), Legate, and Yang (2002), Lidz, and Waxman (2004), Berwick et al. (2011), Chomsky (2013), Perfors, Tenenbaum, and Regier (2011), Reali, and Christiansen (2005), Kam et al. (2008). Elliptical constructions have full, regular interpretations supported by superficially incomplete structures. Since the missing material is manifested in the input only as an absence, it raises the poverty of the stimulus problem in a particularly acute way. If the arguments in this paper are correct, then neither of the two traditional, pleasingly trivial theories of ellipsis are correct: Neither does the ellipsis site lack syntactic structure nor is the structure simply identical to that of the antecedent. Since the correctness of the present, more complex account is revealed only by arcane negative data, we have a genuine poverty of the stimulus problem on our hands. Whatever the correct solution, it must ultimately reveal properties of the initial state or biases of the language acquisition device fairly directly.

The findings reported here reveal their full significance in light of the considerations just discussed. The relatively complex grammar of ellipsis forced by the present data is acquired substantially without relevant evidence. It must therefore constitute the default or one of several alternative defaults (Nevins 2010) of the initial state or the language acquisition device. The answer to the question of whether there is one or several defaults depends on the range of between-language and between-speaker variation. The data reported below are superficially at variance with those in Merchant $(1999,2001)$, who reports that preposition stranding is categorically impossible under sluicing in Bulgarian. Taken at face value this would point to the possible existence of several different idiolects and, correspondingly, several alternative defaults. However, it is possible that the judgments reported by Merchant are intended as a mere preference of one structure over the other, which would be consistent with my own findings and would not lead to the conclusion that there are several defaults. One of my informants has produced the opposite pattern to what is reported here. Whether this is just noise or a real divergence in grammars will have to be determined by broader, carefully controlled data collection with many subjects and a methodology that can distinguish stylistic preferences from more or less categorical effects. This task is not undertaken here. Instead, I will take the judgments I report as true and explore the theoretical consequences. 
The remainder of this paper is structured as follows. Section 2.1. introduces four main facts about sluicing. Together they constitute what I call Ross' dilemma. Section 2.2. introduces the three main approaches to sluicing from the literature and proposes an amendment to Merchant's $(1999,2001)$ approach that allows it to resolve Ross' dilemma. This amendment takes the form of the fit condition, which stipulates that the remnant has to fit into the antecedent replacing the correlate if there is one. Section 2.3. demonstrates some empirical payoffs of the fit condition concerning sprouting, voice alternations, and spray-load alternations - notoriously difficult problems for Merchant's approach without the fit condition. Section 3. discusses the Bulgarian data. I show how the data are accounted for under the current theory and why they are difficult from the perspective of competing approaches that either posit no syntax at the ellipsis site or demand syntactic identity between antecedent and ellipsis site. Section 4. concludes with the discussion of some open issues.

\section{On Sluicing}

This section briefly reviews a few important generalizations about sluicing, 2.1. It then introduces the three main approaches to the phenomenon and suggests an amendment to Merchant's theory of syntactic ellipsis under semantic identity, 2.2. Finally, I demonstrate that the suggested amendment has empirical payoffs substantially beyond the facts immediately motivating it, 2.3.

\subsection{Ross' dilemma}

Ross (1969) was the first generative paper to discuss sluicing. There are four basic facts, all of them explicit or implicit in Ross' discussion, that continue to set the terms of the debate on sluicing to this day. These facts, in the order in which I will discuss them, pertain to the category of the sluice, its interpretation, the case of the remnant, and the apparent scopal properties of the remnant. Together, these four facts constitute a bit of a dilemma, the satisfying resolution of which is the main analytical challenge for theories of sluicing.

In terms of their category, sluices are interrogative clauses no matter what the category of the remnant is. This conclusion rests on commonalities in the distribution of sluices, wh-questions, and declaratives on the one hand and the differences between the distribution of sluices and that expected (on the basis of 
category) of the remnant. Starting with canonical, full wh-questions, their external distribution is not determined by the category of the wh-phrase but arises instead from the clausal syntax of questions and from their semantics. The following examples illustrate the clause-like behavior of questions.

(4) a. *Fritz denkt (dar-) über die Frage, welches Gericht er Fritz thinks there about the question which dish he bestellen soll, nach.

order should after

'Fritz thinks about the question of which dish he should order.'

b. Fritz denkt (*dar-) über nach die Frage, welches Gericht

Fritz thinks there about after the question which dish

er bestellen soll.

he order should

Example (4a) shows that the preposition über takes a noun phrase as its complement but that the prepositional adverb darüber does not. Example (4b) shows that the nominal complement of the preposition cannot extrapose.

(5) a. Fritz denkt *(dar-) über, \{welches Gericht er bestellen soll | Fritz thinks there about which dish he order should dass er bezahlen muss\}, nach.

that he pay must after

'Fritz thinks about [which dish he should order / the fact that he must pay\}.'

b. Fritz denkt ${ }^{*}$ (dar-) über, nach, \{welches Gericht er bestellen Fritz thinks there about after which dish he order soll |dass er bezahlen muss\}. should that he pay must

'Fritz thinks about fwhich dish he should order / the fact that he must pay\}.'

Example (5) illustrates the contrasting behavior of clauses. They cannot function as the complement of prepositions but only of prepositional adverbs, (5a), and they do extrapose, (5b).

The interrogative forms of the prepositional phrase and the prepositional adverb are shown in (6), which are consequently interpreted as wh-questions. 
(6) a. Über was denkt er nach? about what thinks he after 'What is he thinking about?'

b. Wo-r-über denkt er nach? where-R-about thinks he after 'What is he thinking about?'

Embedding an indirect question under a prepositional adverb does not form a wh-constituent, which is why (7) is interpreted as a statement.

(7) Da-r-über, welches Gericht er bestellen soll, denkt Fritz nach. there-R-about which dish he order should thinks Fritz after 'Fritz is thinking about which dish he should order.'

Sluices behave like interrogative clauses and unlike wh-phrases in all respects. They cannot be embedded by prepositions but only by prepositional adverbs, (8a). Like clauses and unlike noun phrases sluices extrapose, (8b).

(8) Fritz weiss, dass er noch ein Gericht bestellen muss,... Fritz knows that he still a dish order must 'Fritz knows that he should still order a dish...

a. und denkt jetzt ${ }^{*}($ da-r- $)$ über, welches Gericht, nach. and thinks now there-R about which dish after and is thinking about which dish'

b. und denkt jetzt ${ }^{*}($ da-r- $)$ über nach, welches Gericht. and thinks now there-R about after which dish and is thinking about which dish'

Furthermore, a prepositional adverb combining with a sluice does not form a whphrase, hence (9) is interpreted as a declarative clause rather than a question.

(9) Fritz wird ein Gericht bestellen, aber darüber, welches Fritz will a dish order but there.R.about which Gericht, denkt er noch nach.

dish thinks he still after

'Fritz will order a dish, but which dish he is still thinking about.' 
All of this leads to the conclusion that, in terms of their category, sluices are interrogative CPs. ${ }^{2}$ Further arguments for this conclusion are given in Merchant (1999, 2001: chapter 2) and it seems uncontroversial (Culicover, and Jackendoff 2005).

The second fundamental fact about sluicing is that sluices are interpreted like full interrogative clauses. Any example of sluicing can be used to illustrate this conclusion, but the fact that (9) immediately above can only be interpreted as a declarative is particularly striking in this regard.

The third discovery was that in sluicing (Ross essentially only looked at merger type sluices) the case of the correlate determines the case of the remnant. For nominal remnants this entails that the case on the remnant is not assigned by the predicate embedding the sluice, if there is one. The basic observation is illustrated in (10).

(10) a. Er hat jemandem geholfen, aber ich weiss nicht \{wem he has someone.DAT helped but I know not who.DAT 1*wen $\quad{ }^{*}$ wer\}.

who.ACC who.NOM

'He helped someone, but I don't know who.'

b. Er hat jemanden unterstützt, aber ich weiss nicht $\left\{{ }^{*}\right.$ wem he has someone.ACC supported but I know not who.DAT / wen $\quad{ }^{*}$ wer\}. who.ACC who.NOM 'He supported someone, but I don't know who.'

c. Jemand ist von ihm unterstützt worden, aber ich weiss nicht someone.NOM is by him supported been but I know not $\left\{{ }^{*}\right.$ wem ${ }^{*}$ wen $\quad$ wer $\}$. who.DAT who.ACC who.NOM 'Someone was supported by him, but I don't know who.'

The case on the remnant in (10) changes with the case of the correlate. When the correlate is in the dative, as demanded by the verb helfen, the remnant must be dative. When the correlate is in the accusative, the case governed by the verb unterstützen, the remnant must be in the accusative. Finally, when the correlate is

2 The conclusion that sluices are clauses does not entail the presence of a (silent) complementizer in the syntax. This conclusion only follows given certain additional assumptions about the endo-centricity of all phrases, an issue I do not discuss here. 
in the nominative carried by subjects, the remnant is in the nominative. The matrix verb wissen itself governs accusative case on its object:

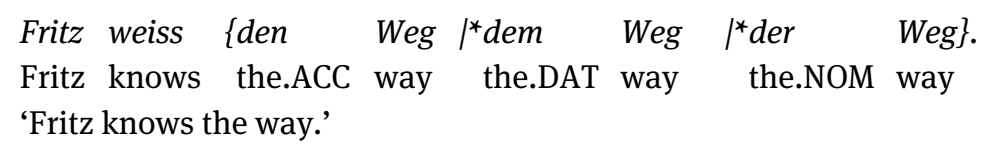

I will refer to this observation as case connectivity.

The forth and final basic discovery about sluicing concerns the apparent scope of the remnant. If we take the antecedent as our guide in constructing a paraphrase for the sluice, we find that sluices can have interpretations corresponding to paraphrases that violate constraints on movement, in particular, island constrains. Thus, example (12) is grammatical and has an interpretation which can be paraphrased as in (13). Example (13) however is ungrammatical, since it violates the complex noun phrase constraint.

(12) They want to hire someone who speaks a Balkan language, but I don't know which (Balkan language).

(13) *They want to hire someone who speaks a Balkan language, but I don't know which Balkan language they want to hire someone who speaks.

I will refer to this class of facts as the island insensitivity of sluicing.

Theories of sluicing face the challenge of accounting for all four of these observations simultaneously. We will see in the next subsection what analytical options there are and why they struggle to meet the challenge.

\subsection{Theories of sluicing}

The four properties just introduced characterize sluicing across a broad range of languages (Merchant 2001, Merchant, and Simpson 2012) and theories of sluicing must account for them. Theories of sluicing must also take a stand on the following two questions: What, if any, is the syntactic representation of the ellipsis site? Is the recoverability condition on ellipsis syntactic or semantic/pragmatic? ${ }^{3} \mathrm{Ac}-$ counts of sluicing (and ellipsis more generally) can profitably be cross-classified

3 As discussed, the lack of direct evidence about these two questions poses a particularly sharp poverty of the stimulus problem for the learner. Essentially, the answer to the questions must be 
by the answers to these two questions, as in the following table, adapted from Merchant (to appear).

Tab. 1: Cross-classification of approaches, adapted from Merchant (to appear)

\begin{tabular}{|c|c|c|}
\hline & \multicolumn{2}{|c|}{ ellipsis site } \\
\hline & contains structure & contains no structure \\
\hline $\begin{array}{l}\text { syntactic } \\
\text { identity }\end{array}$ & $\begin{array}{l}\text { Syntactic identity: Ross (1969), } \\
\text { Chomsky (1972), Lakoff (1970), Sag } \\
\text { (1976), Fiengo, and May (1994), } \\
\text { Chung, Ladusaw, and McCloskey } \\
\text { (1995), Lasnik (2005), Merchant } \\
\text { (2008) }\end{array}$ & N/A (incoherent) \\
\hline $\begin{array}{l}\text { semantic } \\
\text { identity }\end{array}$ & $\begin{array}{l}\text { Semantic identity +: Abels (2011), } \\
\text { Baker, and Brame (1972), Merchant } \\
\text { (2001), van Craenenbroeck (2010a,b), } \\
\text { Barros, Elliott, and Thoms (2014), } \\
\text { Barros (2014), Abels (to appear) }\end{array}$ & $\begin{array}{l}\text { No syntax at ellipsis site: } \\
\text { Dalrymple, Sheiber, and Pereira (1991), } \\
\text { Ginzburg, and Sag (2000), Culicover, } \\
\text { and Jackendoff (2005) }\end{array}$ \\
\hline
\end{tabular}

The two simplest accounts of sluicing are the ones in the top left and the bottom right corner of the table. The top left represents theories according to which there is syntactic structure at the ellipsis site and the recoverability condition is a syntactic one. On these accounts, the recoverability condition demands, roughly, syntactic identity (or isomorphism) between antecedent and ellipsis site. I will refer to this class of accounts as syntactic identity accounts. Syntactic identity accounts contrast with a class of theories, in the bottom right of the table, that deny the existence of (context dependent) structure at the ellipsis site and that posit semantic/pragmatic recoverability conditions. I will refer to these accounts as the no-syntax accounts. No theories are listed in the top right corner of the

provided more or less directly by defaults of universal grammar. Speakers converge across languages and evidence that would override the defaults is lacking in the primary linguistic data. The table below indicates that questions about the nature of the ellipsis site and the recoverability condition have not been settled in linguistic theory despite substantial attention to the issues. This reinforces, in my view, the poverty of the stimulus argument: since syntacticians have access to more (including negative) and more controlled data than learners with the added advantage that the syntacticans' data can be annotated for acceptability and interpretation. Despite all of these advantages, syntacticians have not been able to agree on an answer to the question whether there is syntactic structure present at the ellipsis site. 
table because, for a theory to fall into that cell, it would have to make the incoherent demand that there is no (contextually variable) structure at the ellipsis site and that the recoverability condition on ellipsis is syntactic in nature. Finally, the bottom left hand cell is occupied by accounts that assume the presence of contextually varying syntactic structure at the ellipsis site but hold that the recoverability condition is semantic/pragmatic rather than syntactic. They are designated as "semantic identity +" because to reach descriptive adequacy they have to add further constraints to the simple semantic identity condition. The present paper endorses this type of approach. As we will see promptly, what answer a theory gives to these two questions strongly guides its account of the four observations from the previous subsection.

Turning to syntactic identity accounts first, they posit that there is full fledged syntactic structure at the ellipsis site at the point of the derivation/level of representation relevant to interpretation. The structure is either silenced or absent at the point of the derivation/level of representation relevant to pronunciation. These accounts also assume that, modulo wh-movement of the remnant, the ellipsis site is structurally identical to the antecedent or very nearly so. Such accounts have a straightforward explanation for the observation that sluices behave like clauses (The sluice is a clause under such approaches.), that the sluice is interpreted as a full interrogative clause (That's what it is.), and for case connectivity. Case connectivity follows from the assumption that antecedent and ellipsis site have identical structure, which, of course, entails identity of case governors. ${ }^{4}$ The principal problems for syntactic identity are the island insensitivity of sluicing and a host of cases that do not lend themselves to an analysis in terms of strict syntactic identity, because strictly identical paraphrases of the sluice are either impossible or have the wrong interpretation (see Merchant 2001: chapter 1 for review). The island repair problem has given rise to a substantial literature (for review and references see Barros, Elliott, and Thoms 2014, Abels to appear), but the proposed solutions are often stipulative (see Culicover, and Jackendoff 2005 for this point) or fail to address the further wrinkle that locality sensitivity returns in multiple sluicing (see for example Takahashi (1994), Lasnik (2014), Nishigauchi (1998), Marušič, and Žaucer (2013)) and contrast sluicing (see for example Fukaya 2012, 2007, Griffiths, and Lipták 2011, Winkler 2013).

\footnotetext{
4 Van Craenenbroeck (2010a) proposes that a looser version of syntactic congruence should be used with the choice between alternatives regulated by last resort (see also Kim et al. 2011). The main problem here is to define the conditions under which non-identical structures can be allowed. The discussion here ignores such refinements and concentrates on the basic syntactic identity approach.
} 
Despite the problems in accounting for island insensitivity, syntactic identity accounts have enjoyed enduring popularity, probably because the analysis of the first three properties of sluicing is simple and convincing. In particular, case connectivity is often viewed all by itself as convincing evidence for the existence of identical syntactic structure at the ellipsis site. The argument is based on the prior conviction that case is a syntactic phenomenon and that it follows from properties of universal grammar that there must be an inaudible case licenser for the remnant in sluicing. This fact is tied elegantly to the semantic congruence between antecedent and sluice by syntactic identity accounts. The only otherwise unmotivated assumption that needs to be added to universal grammar is that ellipsis is recovered under syntactic identity. ${ }^{5}$ It is this trivialization of ellipsis that makes syntactic identity accounts so appealing.

Approaches where there is no (contextually variable) syntactic structure at the ellipsis site typically take a more surface-oriented, less abstract approach to syntactic structure generally. Sluicing is then viewed as a subtype of interrogative constructions. This classification can be learned from semantic evidence. The classification endows sluices by default inheritance mechanism with clausal syntactic structure. Island insensitivity of sluicing follows directly from the assumption that there is no structure at the ellipsis site: structural constraints on displacement cannot play a role when there is no structure. This leaves case connectivity in need of an account. Here, no-syntax approaches invoke a relation between correlate and remnant whereby the remnant or the remnant's case is anaphorically related to the correlate's.

The principal problem here is that the account is too loose. Language internally, this plays out as an overgeneration issue. A relevant case is given in (14).

(14) a. Mary is proud of someone, but she won't tell us (of) who.

b. Mary is proud, but she won't tell us ${ }^{*}$ (of) who.

Semantically, the version of (14b) with and without the preposition of are fully synonymous, yet, the preposition of is required, which must be attributed to syntax. The only syntactic consideration entering the account has to do with anaphoric case on the remnant. In (14b), the remnant has no correlate, hence, nothing to be anaphoric to. However, this alone cannot be the explanation for why the preposition is required, since in many other cases a remnant without a casemarked correlate is possible without a preposition as part of the remnant, (15).

5 I am ignoring here and throughout questions of ellipsis licensing distinct from ellipsis recoverability. For work on ellipsis licensing see Aelbrecht (2010), Lobeck (1987), Johnson (1996). 
Thus, there seems to be no non-stipulative way to account for the obligatory presence of of in (14b): As it stands, the account is too loose.

\section{John will eat, but I don't know what.}

The looseness of the account manifests itself in a different form cross-linguistically. It is unclear why case connectivity should hold across languages. A language where, for example, default case instead of anaphoric case is used on the remnant seems plausible, but we don't seem to encounter such languages. Finally, the island insensitivity of sluicing is derived in such a deep way in no-syntax accounts, that they fail to offer any approach to contrast and multiple sluicing, where we do find locality effects.

Merchant (1999, 2001) develops an account that combines a semantic condition of recoverability of deletion with the assumption that there is syntactic structure at the ellipsis site. This explains the clausal categorial and interpretive behavior of sluicing directly. This way of approaching the phenomenon has the additional advantage of allowing for cases where syntactic identity is too strict: as long as the structure at the ellipsis site gives rise to an interpretation that can be recovered, its syntax may deviate from that in the antecedent. Merchant suggests that this possibility of a syntactic mismatch between antecedent and ellipsis site explains island insensitivity (at least in part); when island effects are avoided, there is a synonymous non-island violating paraphrase acting as presluice. This logic can then be used to argue that when island sensitivity is observed, this is due to the absence of a non-island violating paraphrase (Fukaya 2007, 2012, Marušič, and Žaucer 2013, Abels to appear, Barros, Elliott, and Thoms 2014).

While the idea is an attractive one, it is unclear how it accounts for case connectivity. In example (10a) above the case governor in the antecedent is the verb helfen, which assigns dative case. One might expect violations of case connectivity if any of the following paraphrases were allowed at the ellipsis site as presluices:

$$
\begin{aligned}
& \text { (16) a. ... wen er unterstützt hat. } \\
& \text { who.ACC he supported has } \\
& \text { '...who he supported.' } \\
& \text { b. ... wer es ist, dem er geholfen hat. } \\
& \text { who.NOM it is that.DAT he helped has } \\
& \text { '...who it is that he helped.' }
\end{aligned}
$$




\section{c. ... wer von ihm geholfen gekriegt hat. who.NOM by him helped become has '...who was helped by him.'}

In addition, examples like (14) are problematic under Merchant's account, because both she is proud of $t_{\mathrm{NP}}$ and she is proud $t_{\mathrm{PP}}$ appear to be semantically recoverable in the same way from the antecedent she is proud. These considerations are at the heart of Lasnik's (2005) objections to Merchant's theory.

To solve the problem of case connectivity for Merchant's approach, I would like to propose a condition that I call fit. ${ }^{6}$
Fit condition
Modulo agreement in the antecedent and wh-movement, replacing the correlate by the remnant in the antecedent must lead to a syntactically well-formed structure with the right meaning or - for sprouting - adding the correlate into the antecedent and making no further changes must lead to a syntactically well-formed structure with the intended thematic interpretation. (Compare also Barker 2013.)

The fit condition is intended to express the fact that, ignoring the need for the remnant to undergo wh-movement, the remnant must be able to grammatically replace the correlate in the antecedent under the relevant thematic interpretation. By assumption, there is also structure at the ellipsis site and the remnant is moved from it. Therefore, the remnant also fits into the structure at the ellipsis site. Under this approach, the remnant is like a piece of a puzzle that fits in two places: It fits into the antecedent (by the fit condition) and it fits into the structure at the ellipsis site (by normal assumptions about structure and movement).

As formulated above, the fit condition is clearly not precise enough. We will want to say that in German a noun phrase in the nominative does not fit into a slot for a dative noun phrase when the two are morphologically distinct. But there is a real question about examples where there is case syncretism. It is known that some processes such as free relatives are sensitive to purely morphological fitting. Other processes require identity of syntactic case. We will see some evidence

6 There are, of course, other avenues open. We could try to explicitly limit the syntactic differences between antecedent and ellipsis site (Chung, Ladusaw, and McCloskey 2011, Chung 2013) or stipulate case connectivity. It should also be noted that the fit condition can in principle be bolted on to any of the other approaches to sluicing. It should become clear why I opt for the specific combination of assumptions I do. 
bearing on the question of how to make the fit condition precise in the next section, but will have to leave aside the task of formulating fit with full precision. Note also that, in order to reach explanatory adequacy, it needs to be shown how the fit generalization follows from principles of universal grammar as a default. Again, I will not undertake this task here and will make only the briefest of comments in the conclusion to the paper.

The three approaches to sluicing can be summarized by the following three diagrams that show the overall logic. In a syntactic identity approach, case connectivity follows from syntactic identity between antecedent and pre-sluice, but this raises the problem of why sluicing is island insensitive and why certain mismatches are allowed. No-syntax approaches can explain the lack of island effects directly, but need to stipulate case connectivity via a special case copying mechanism that lies outside of normal case assignment mechanisms. Finally, the current approach demands semantic identity between antecedent and sluice while allowing syntactic mismatches. This explains the island insensitivity of sluicing. Case connectivity is explained in terms of the fit condition, which guarantees that the remnant can locally fit not only into the pre-sluice but also (modulo movement) into the antecedent.

(18) a. Syntactic identity:

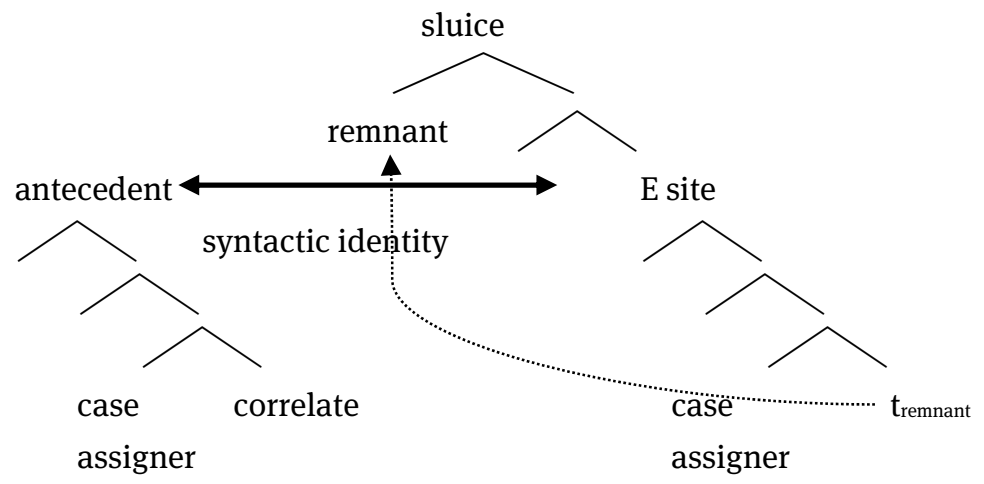


b. No syntax at ellipsis site:

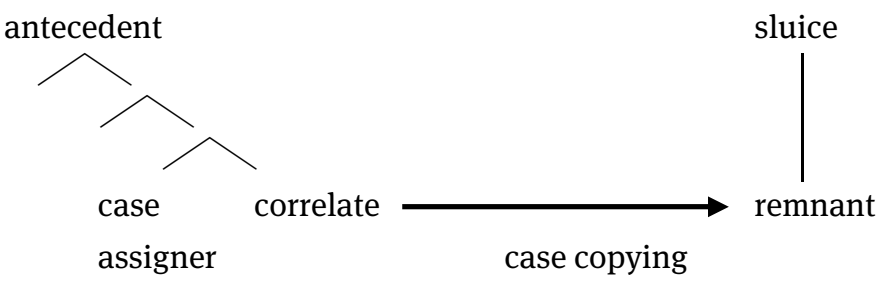

c. Semantic identity with syntax at ellipsis site and fit condition:

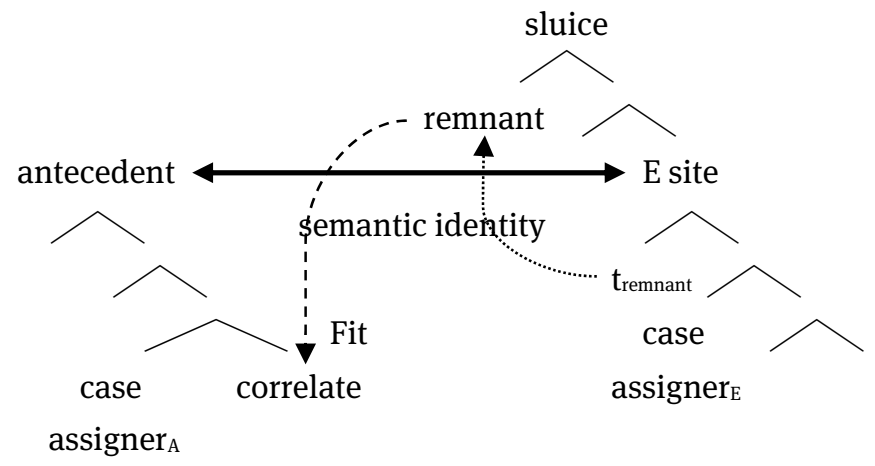

\subsection{Fit at work}

In the previous subsection we considered the paradigm in (14), repeated below.

(19) a. Mary is proud of someone, but she won't tell us

(i) who.

(ii) of who.

b. Mary is proud, but she won't tell us
(i) ${ }^{*}$ who.
(ii) of who.

The examples are notoriously difficult for accounts positing a semantic identity condition, essentially, because of is semantically vacuous syntactic glue, which can be stranded under wh-movement: 
(20) a. Who is she proud of?

b. Of who is she proud?

The problem is solved by the fit condition. The remnant in (19a-i) is who, the correlate is someone. Who fits into the position of someone modulo movement. In (19a-ii) the correlate is of someone. Again, modulo movement, the well-formed prepositional phrase of who fits in the position of the correlate. In (19b) there is no correlate and who does not fit into the antecedent clause. The sprouted argument of proud fits into the antecedent only when of is present:

(21) a. She is proud ${ }^{*}($ of $)$ someone.

b. Who is she proud ${ }^{*}(o f)$ ?

This is how the fit condition solves the problem of why preposition stranding appears to be disallowed under sprouting.

The same essential logic applies to voice alternations, which are notoriously troublesome for semantic identity accounts. The problem can be illustrated by the following examples:

(22) John was arrested, but the report doesn't say which officer.

(23) *Some officer arrested John, but the report doesn't say by which officer.

The sluice in (22) cannot be interpreted to mean which officer arrested John. ${ }^{7}$ Given that the antecedent in (22) entails that someone or some officer arrested John, the following pre-sluices should be recoverable:

(24) a. ...which officer John was arrested by.

b. ...which officer arrested John.

Thus, sluicing should be allowed under the relevant interpretation. We can account for the fact that it is not by invoking the fit condition: an agent noun phrase does not fit into the passive antecedent without the addition of $b y$, which is therefore required for a well-formed sluice:

(25) John was arrested, but I don't know by which officer.

7 The interpretation that (22) has is a contrastive one suggesting that John and an unknown officer were arrested. This is unproblematic and irrelevant here. 
Example (23) suffers from the opposite problem: the superfluous presence of by. Again there is a well-formed, recoverable pre-sluice:

$$
\text { ...by which officer John was arrested. }
$$

The ungrammaticality follows from the fit condition, because the agent cannot be expressed as a by-phrase in the antecedent.

The same solution works for the difficult case of spray-load alternations. Again, semantic identity accounts run into issues of over-generation. The problem can be illustrated by the following examples:

(27) He loaded something onto the wagon, but I don't know with what.

(28) ${ }^{*}$ He loaded some wagon with hay, but I don't know onto which wagon.

The question is why the sluice in (27) can only be interpreted as a question about the instrument of loading but not as the object being loaded and why (28) is ungrammatical, given the in-principle availability and recoverability of the following pre-sluices:

...with what he loaded the wagon.

...onto which wagon he loaded the hay.

The fit condition provides the answer to this problem. A prepositional phrase headed by with fits into the antecedent in (27), but only with an instrument reading, so that is the reading we derive. The prepositional phrase headed by onto does not fit into the antecedent in (28).

The discussion in this subsection was meant neither as a justification of the fit condition nor as an exhaustive demonstration of its analytic value and certainly not as a discussion of its problems and limitations. Instead, it was intended as a brief illustration of its power and potential value. Most of all I hope to have created a sense for the style of analysis necessary under the current approach, where a syntactic well-formed pre-sluice undergoes ellipsis under semantic identity with the antecedent and the remnant is subject to the fit condition. This style of analysis requires the remnant to be part of (and therefore fit into) a well-formed pre-sluice and into the antecedent. In the next section, I will apply this style of analysis to unfamiliar data involving the interaction of Bulgarian preposition stranding, case morphology, and sluicing. 


\section{Bulgarian}

In this section I present Bulgarian data which fall out quite directly from the setup here but which are difficult to explain under alternative accounts, in particular the syntactic identity and the no-syntax accounts. Before turning to the sluicing data, I need to introduce a few facts of Bulgarian grammar as background. First, modern Bulgarian has lost almost all case distinctions that were present historically. There is no distinction between subject and object case, except in pronouns, including indefinite and interrogative pronouns and in the definite article. Even for pronouns, the distinction is only optionally expressed in the sense that there is a general form (glossed as g) which can appear in the position of subject, object, and object of prepositions. The other form (historically an accusative and glossed as non-S) is restricted to the positions of object and object of prepositions, (31). The object form of the pronoun is somewhat formal and archaic. $^{8}$

(31) a. Ivan sreshtna \{njakoi |njakogo\}.

Ivan met.3SG someone.G someone.NON-S

'Ivan met someone.'

b. Ivan tancuva $\{\mathrm{s}$ njakoi ls njakogo\}.

Ivan danced with someone.G with someone.NON-S

'Ivan danced with someone.'

c. $\left\{\right.$ Njakoi $\quad{ }^{*}$ Njakogo $\} \quad$ tancuva.

someone.G someone.NON-S danced

'Someone danced.'

The other fact about Bulgarian that we will rely on is that preposition stranding is disallowed independently of the form of the interrogative pronoun used: $\begin{array}{lllll}\text { a. } S & \{k o i & \mid k o g o & \text { tancuva } & \text { Ivan } \\ \text { with } & \text { who.G } & \text { who.NON-S danced } & \text { Ivan }\end{array}$ ? 'With who did Ivan dance?'
b. ${ }^{*}$ Koi tancuva $\{\mathrm{s}$ Ivan /Ivan $s$ who.G danced with Ivan Ivan with
c. ${ }^{*}$ Kogo tancuva $\{\mathrm{s}$ who.NON-S danced with Ivan Ivan with

8 For further discussion see Scatton (1993). 
Object sluices in Bulgarian allow arbitrary combinations of general form and object form of the pronouns in correlate and remnant, (33), though there is a stylistic preference for matching forms in antecedent and remnant. Subject sluices, are, of course, limited to the general form of the pronoun, (34).

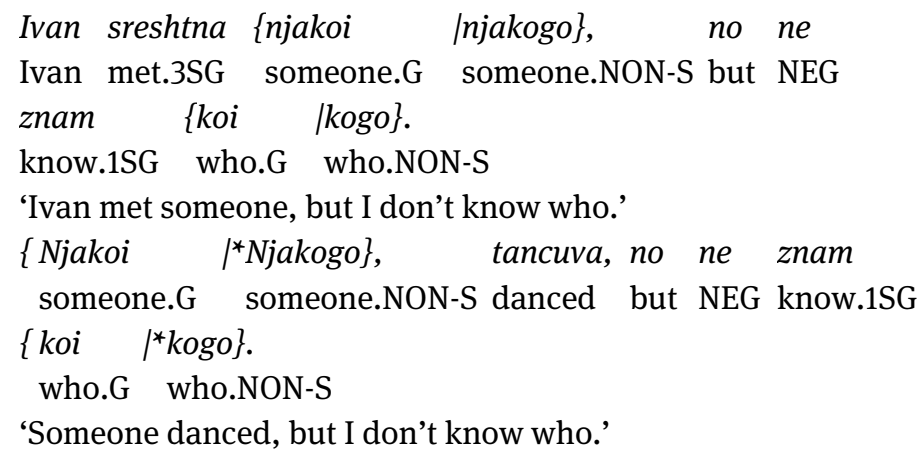

The same range of possibilities exists in full questions.

Ivan sreshtna njakoi |njakogo\}, no ne znam
Ivan met.3SG someone.G someone.NON-S but NEG know.1SG
$\{$ koi |kogo\} sreshtna Ivan.
who.G who.NON-S met Ivan
'Ivan met someone, but I don't know who Ivan met.'
$\left\{\right.$ Njakoi $\left.\right|^{*}$ Njakogo\}, tancuva, no ne znam
someone.G someone.NON-S danced but NEG know.1SG
$\left\{\right.$ koi $\left.\right|^{*}$ kogo $\}$ tancuva.
who.G who.NON-S danced
'Someone danced, but I don't know who danced.'

This state of affairs is, of course, as expected under the current account. Both forms of the object pronoun give rise to well-formed pre-sluices. For (33) both forms fit into the antecedent. In (34) only the general form fits. This accounts for the restriction seen in (34) even if a suitable pre-sluice could be found that licenses the object form of the pronoun. Syntactic identity theories have an obvious account of these facts, too. Finally, no-syntax accounts require a somewhat abstract view of case, whereby the pronoun in positions that are compatible with both forms share a property (say acc) not present in environments where only the general form is possible. To account for the facts above, the anaphoric relation licensing case on the remnant must be sensitive to this abstract feature rather 
than to the morphological form. If these assumptions are adopted, the data above can be accounted for.

When we turn to questions with prepositions, things become more interesting. If the preposition is part of the remnant, both case forms of the pronoun are allowed - as in full questions - and correlate remnant mismatches are possible in both directions, (37).

Ivan tancuva $\{s$ njakoj ls njakogo\}, no ne
Ivan danced with someone.G with someone.NON-S but NEG
znam $\{s \quad$ koi $/ s \quad$ kogo $\}$.
know with who.G with who.NON-S
'Ivan danced with someone but I don't know with who.'

Given what we said in the previous paragraph, this is unsurprising under any account.

However, some speakers also allow apparent preposition stranding under sluicing. Example (38) illustrates the situation for remnants with the general form of the pronoun. We will discuss examples with the object form in the next paragraph.

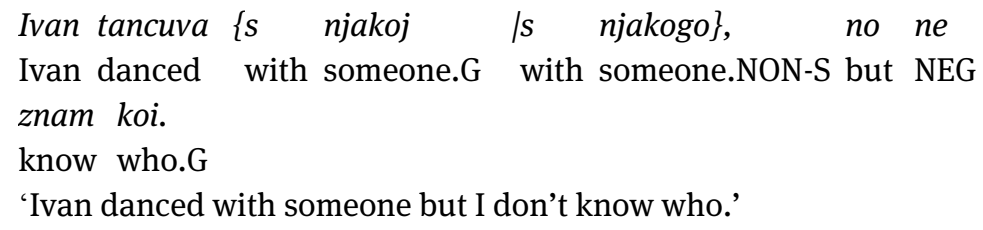

The situation in (38) is not particularly surprising under no-syntax accounts: pied-piping of the preposition is a purely syntactic phenomenon accompanying movement. Since there is no movement in the derivation of sluicing, pied-piping need not happen, hence, the well-formedness of (38) is expected. Example (38) is problematic under syntactic identity accounts, because the sluice would have to be derived from the ill-formed pre-sluice (32b) and should therefore be ungrammatical. The current account allows a mismatch between the syntax of the antecedent and the syntactic structure at the ellipsis site. Under the current approach, (32b) is not the only pre-sluice. We also need to consider (39). (39) is well-formed and semantically recoverable. 
(39)

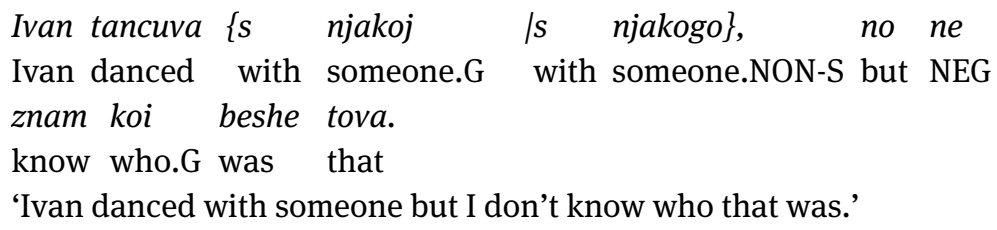

The general form of the pronoun we find in (39) fits into the antecedent. Hence, (38) has (39) as recoverable, well-formed source and the remnant fits into the antecedent. This makes the acceptability of (38) the expected state of affairs.

Things change when we consider (40), which differs from (38) only in the form of the pronoun in the remnant. The example is unacceptable.

Ivan tancuva $\{\mathrm{s}$ njakoj ls njakogo\}, no ne
Ivan danced with someone.G with someone.NON-S but NEG
znam kogo.
know.1SG who.NON-S
'Ivan danced with someone but I don't know who.'

As far as I can see, this is mysterious under no-syntax accounts. Syntactic identity accounts explain (40) straightforwardly. The pre-sluice involves preposition stranding, (32c), and is, therefore, ungrammatical. The copulative sentence that we invoked as the pre-sluice for (38) does not allow the object form of the pronoun:

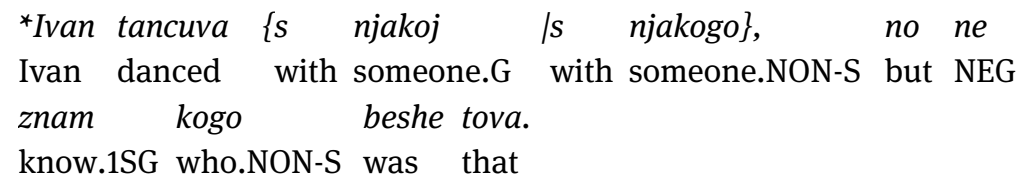

Lacking a plausible, well-formed, recoverable pre-sluice, (40) is correctly predicted to be ungrammatical.

The discussion of (38) and (40) can be summarized in the table below, which shows that, amongst the three accounts considered here, only the semantic identity account with structure at the ellipsis site and the fit condition explains the 
data. Neither of the other account can deal with the reversal of the judgment depending on the form of the remnant. ${ }^{9}$

Tab. 2: Acceptability of stranding by remnant

\begin{tabular}{llll}
\hline & & wh.G $\checkmark$ & wh.non-S * \\
\hline Judgement & syntactic identity & no & yes \\
$\begin{array}{l}\text { agrees with pre- } \\
\text { diction }\end{array}$ & no-syntax & yes & no \\
& here & yes & yes \\
\hline
\end{tabular}

The reversal of the judgments depending on the form of the remnant precludes a language-wide solution that could be bolted onto syntactic identity or no syntax accounts. The obvious way to go would be to add conditions regulating how the form of the pronoun interacts with stranding under sluicing directly. The current account has a markedly different logic, since the availability of stranding depends on the availability of a suitable, well-formed, recoverable pre-sluice. Neither of the other theories leave room for maneuver in this direction. No syntax accounts cannot invoke the structure present at the ellipsis site, since they deny it is there. Syntactic identity accounts cannot invoke a structure different from the antecedent without giving up the central assumption of the account (and the explanation of case connectivity).

The rest of this section will present two additional arguments suggesting that what matters is the availability of a well-formed, recoverable pre-sluice rather than the form of the pronoun per se. The arguments are straightforward: Stranding even of the general form of the pronoun becomes impossible when the copulative structure in (39) argued to provide the pre-sluice for (38) is unavailable for reasons other than the form of the pronoun.

The first argument comes from contrast sluicing. So far, we have concentrated on Chung, Ladusaw, and McCloskey's merger type of sluicing. However, Bulgarian - like English - also allows contrast sluices, where the remnant queries the identity of an alternative to the correlate:

9 The Bulgarian default pronouns behave like Spanish and Brazilian Portuguese, as described in Rodrigues, Nevins, and Vicente (2009). The object pronouns behave like German, as described in Merchant (2001). This is not an accident under the current theory. 

Ivan tragna, no ne znam koi oshte. Ivan left but NEG know.1SG who else 'Ivan left, but I don't know who else.'

Again like in English, the pre-sluice for such examples cannot be a copulative structure like (39) above, (43a), while a regular full question does work as a presulice, (43b):
a. ${ }^{*}$ Ivan tragna, no ne znam koi oshte beshe tova. Ivan left but NEG know.1SG who else was that *'Ivan left, but I don't know who else it is.'
b. Ivan tragna, no ne znam koi oshte tragna. Ivan left but NEG know.1SG who else left 'Ivan left, but I don't know who else left.'

The important observation is that contrast sluicing in Bulgarian requires the presence of the preposition independently of the form of the pronoun.
(44) Ivan tancuva s Maria, no ne znam ${ }^{*}(s) \quad\{k o i \quad \mid k o g o\}$ Ivan danced with Maria but NEG know with who.G who.NON-S oshte.
else
'Ivan danced with Maria, but I don't know with who else.'

This is as expected under the current approach but it compounds the difficulties for the no-syntax and syntactic identity approaches, since, under both accounts, the status of an example cannot depend on the syntactic status of a paraphrase that is not isomorphic to the antecedent.

The second argument comes from multiple sluicing. Prepositions must be retained in multiple sluicing, independently of the form of the pronoun:

$$
\begin{aligned}
& \text { Ivan zapozna njakoi s } \text { \{njakogo |njakoi\}, } \\
& \text { Ivan introduced someone.G with someone.NON-S someone.G } \\
& \text { no ne znam koi *(s) }\{\text { kogo } \quad \text { koi }\} \text {. } \\
& \text { but NEG know.1SG who with who.NON-S who.G } \\
& \text { 'Ivan introduced someone to someone, but I don't know who to who.' }
\end{aligned}
$$

This is as expected under the current account, because the identificational beshe tova-'was that' sentence that was suggested as the pre-sluice for the stranding 
example above only allows a single predicate. The no-syntax and syntactic identity accounts, again, struggle to come to grips with these examples.

In this section I hope to have shown that the complex interaction of preposition stranding and sluicing with pronominal morphology in Bulgarian cannot be explained without making reference to the grammatical status of a range of different potential pre-sluices. Since such reference is incompatible both with syntactic identity and with no-syntax accounts, this conclusion serves as an argument against all such accounts. I take the ease with which the pattern flows from the current account to be a strong argument in its favor.

\section{Conclusion}

This paper has proposed the fit condition as an amendment to Merchant's theory of sluicing. The fit condition demands that the remnant must fit into the antecedent, replacing the correlate if there is one. After illustrating a few of the immediate benefits of fit for the analysis of sluicing in English, I presented a novel set of data from Bulgarian, partially at variance with judgments from the literature, that strongly suggest the current approach.

In these final paragraphs I would like to discuss some of the most obvious open issues. These are the issue of idiolectal and dialectal variation, the exact content of the fit condition, and a possible approach to the question of why fit might be a default of universal grammar, as it has to be if the reflections from the introduction on ellipsis as a particularly acute poverty of the stimulus situation are correct. I will take these up in the order given.

Merchant $(1999,2001)$ reports that preposition stranding under sluicing is impossible in Bulgarian. His data involve pronouns in the default form, this is the type of examples reported here to allow preposition stranding under sluicing. The judgment reported by Merchant is not entirely surprising. My own informants prefer the version with the preposition over the version without it in all conditions. Yet, there is a sharp contrast in the prepositionless version between the general and the object form of the wh-pronoun. Thus, there is not necessarily a contradiction in the facts as I report them and as Merchant does. A second reason not to be too surprised comes from the fact that the copulative pre-sluice underlying the prepositionless version appears not to be immediately available for some speakers but emerges only on reflection, altering the judgment on prepositionless sluice. Work with more informants designed to distinguish mere preferences from more categorical effects should be able to determine whether there is 
a split in the population or not. I have run into one informant who prefers stranding with the object form of the pronoun and rejects it with the general form. Again, further work is necessary to determine whether this data point represents a genuine dialect or idiolect or is just noise.

A second issue that requires attention has to do with the exact formulation and content of the fit condition. We have seen for Bulgarian that the superficial morphology of the wh-word matters. For the fit condition to work properly in example (38), the wh-pronoun, which is a subject in the pre-sluice, must be able to fit into the antecedent's complement position within the prepositional phrase. This is possible if fit references the superficial shape of the wh-pronoun. Otherwise, the syncretism couldn't be made to matter. On the other hand, it is not true that superficial syncretism is always the overriding factor for preposition stranding under sluicing. Consider the following German examples:

(46) a. Hans hat auf etwas gesessen, aber ich sagedir nicht
Hans has on something sat but I say you not
*(auf) was.
on what.NOM/DAT
'Hans has sat on something, but I won't tell you (on) what.'
b. Hans hat auf jemandem gesessen, aber ich
Hans has on someone.DAT sat $\quad$ but I
sage dir nicht $\left\{{ }^{*}(\right.$ auf $)$ wem $\left.\right|^{*}$ wer $\}$.
say you not on who.NOM who.NOM
'Hans has sat on someone, but I won't tell you (on) who.'

If the overriding factor were simply surface syncretism, we would expect (46a) to allow stranding under sluicing, because there is a copulative source and the remnant wh-pronoun was is syncretic between nominative and dative. And there should, crucially, be a contrast between (46a) and (46b), because in the latter the remnant wh-phrase is not syncretic in the same way. However, at least in my own judgment, this effect does not show up. ${ }^{10}$ Similarly for Polish. Polish has nominative-accusative syncretism in inanimate masculine and neuter forms but not in animate masculine and feminine ones. As far as I have been able to determine, the judgments on preposition stranding under sluicing seem unaffected by this.

10 For me, which-phrases allow preposition stranding under sluicing but remain degraded unless the part of the noun phrase following, which is also elided. Again, case syncretism does not seem to affect the judgment. Even for which-phrases, preposition stranding becomes much worse in contrast and multiple sluicing. 
Clearly, too naive a formulation of fit in terms of superficial morphological forms would give rise to the expectation that syncretism should always matter and one in terms of abstract case alone would give rise to the expectation that it never does. It is, at present, unclear how to find the proper balance or whether some kind of parameterization is required.

The final question to be discussed here arises in the context of the considerations about the poverty of the stimulus problem from the introduction. How is a system as complicated as the Bulgarian one acquired? In particular, what allows the fit condition to be a default of the language acquisition device? The answer to this question might be tied to the following considerations. Wh-phrases are standardly thought of as foci. If they are foci, then they generate a set of alternatives. In merger type and contrast sluicing, the correlate is usually focused and thus gives rise to a set of alternatives as well. Plausibly, the remnant and correlate are focus alternatives to each other. Under a structural (rather than a semantic) theory of focus alternatives along the lines of Katzir (2008), Fox, and Katzir (2011) it seems natural to impose the condition that the generated alternatives must fit in the position of the generator. Thus, if structurally generated alternatives are used to create coherence between antecedent and sluice, then the fit condition might follow from the imposition that the remnant and correlate be structural focus alternatives to each other. Working out the details of this poses a number of challenges and the issue must be left open here.

\section{References}

Abels, Klaus. 2011. Don't repair that island! It ain't broke. Talk presented at Islands in Contemporary Linguistic Theory.

Abels, Klaus. to appear. Movement and islands. In Jeroen van Craenenbroeck, and Tanja Temmerman (eds.), The Oxford handbook of ellipsis, chap. 15. Oxford: Oxford University Press.

Aelbrecht, Lobke. 2010. The syntactic licensing of ellipsis. Werner Abraham, and Elly van Gelderen (eds.). Vol. 149 (LA). Amsterdam \& Philadelphia: John Benjamins Publishing Company.

Baker, C. L., and Michael Brame. 1972. 'Global rules': a rejoinder. Language 48(1). 51-75.

Barker, Chris. 2013. Scopability and sluicing. Linguistics and Philosophy 36.187-223.

Barros, Matthew. 2014. Sluicing and identity in ellipsis. New Brunswick: Rutgers University $\mathrm{PhD}$ thesis.

Barros, Matthew, Patrick D. Elliott, and Gary Thoms. 2014. There is no island repair. Ms. Rutgers, UCL, University of Edinburgh.

Berwick, Robert C. et al. 2011. Poverty of the stimulus revisited. Cognitive Science. 1207-1242.

Chomsky, Noam. 1972. Some empirical issues in the theory of transformational grammar. In Stanley Peters (ed.), The goals of linguistic theory, 63-130. Englewood Cliffs, New Jersey: Prentice-Hall. 
Chomsky, Noam. 2013. Poverty of the stimulus: willingness to be puzzled. In Massimo PiatelliPalmarini, and Robert C. Berwick (eds.), Rich languages from poor inputs, 61-67. Oxford: Oxford University Press.

Chung, Sandra. 2013. Syntactic identity in sluicing: how much and why. Linguistic Inquiry 44(1). 1-44.

Chung, Sandra, William A. Ladusaw, and James McCloskey. 1995. Sluicing and logical form. Natural Language Semantics 3. 239-282.

Chung, Sandra, William A. Ladusaw, and James McCloskey. 2011. Sluicing(:) Between Structure and Inference. Ms. UCSC.

van Craenenbroeck, Jeroen. 2010a. Invisible last resort: a note on clefts as the underlying source for sluicing. Lingua 120(7). 1714-1726.

van Craenenbroeck, Jeroen. 2010b. The syntax of ellipsis (Oxford Studies in Comparative Syntax). Oxford: Oxford University Press.

van Craenenbroeck, Jeroen, and Tanja Temmerman (eds.). to appear. The Oxford handbook of ellipsis. Oxford: Oxford University Press.

Culicover, Peter W, and Ray S Jackendoff. 2005. Simpler syntax. Oxford: Oxford University Press.

Dalrymple, Mary, Stuart M. Sheiber, and Fernando C. N. Pereira. 1991. Ellipsis and higher-order unification. Linguistics and Philosophy 14(4). 399-452.

Dayal, Veneeta, and Roger Schwarzschild. 2010. Definite inner antecedents and wh-correlates in sluicing. In Peter Staroverov et al. (eds.), Rutgers working papers in linguistics, vol. 3, 92-114. LGSA.

Fiengo, Robert, and Robert May. 1994. Indices and identity. Cambridge, MA.: MIT Press.

Fox, Danny, and Roni Katzir. 2011. On the characterization of alternatives. Natural Language Semantics 19. 87-107.

Fukaya, Teruhiko. 2007. Sluicing and stripping in Japanese and some implications. Los Angeles, CA: University of Southern California PhD thesis.

Fukaya, Teruhiko. 2012. Island-sensitivity in Japanese sluicing and some implications. In Jason Merchant, and Andrew Simpson (eds.), Sluicing: cross-linguistic perspectives, vol. 38 (0xford Studies in Theoretical Linguistics), 123-163. Oxford: Oxford University Press.

Ginzburg, Jonathan, and Ivan A. Sag. 2000. Interrogative investigations: the form, meaning, and use of English interrogatives. Stanford, CA: CSLI Publications.

Griffiths, James, and Anikó Lipták. 2011. Contrast and island-sensitivity in clausal ellipsis. Ms. University of Leiden.

Johnson, Kyle. 1996. When verb phrases go missing. GLOT International 2(5). 2-9.

Kam, Xuân-Nga Cao et al. 2008. Bigrams and the richness of the stimulus. Cognitive Science 32. 771-787.

Katzir, Roni. 2008. Structural competition in grammar. Cambridge, Mass.: MIT PhD thesis. Kim, Christina S. et al. 2011. The acceptability cline in VP ellipsis. Syntax (14). 318-354.

Lakoff, George. 1970. Global rules. Language 46. 627-639.

Lasnik, Howard. 2001. When can you save a structure by destroying it? In Minjoo Kim, and Uri Strauss (eds.), Proceedings of the north east linguistic society 31, 301-320. Georgetown University: GLSA.

Lasnik, Howard. 2005. The syntax of silence. by Jason Merchant. Language 81(1). 259-265.

Lasnik, Howard. 2014. Multiple sluicing in English? Syntax 17(1). 1-20.

Legate, JA, and CD Yang. 2002. Empirical reassessment of poverty of stimulus arguments. Reply to Pullum and Scholz. Linguistic Rev 19. 151-162. 
Lidz, Jeffrey, and S Waxman. 2004. Reaffirming the poverty of stimulus argument: a reply to the replies. Cognition 93. (1)57-165.

Lobeck, Anne. 1987. Syntactic constraints on ellipsis. Seattle: University of Washington PhD thesis.

Marušič, Franc, and Rok Žaucer. 2013. A note on sluicing and island repair. In Steven Franks (ed.), Annual workshop on formal approaches to slavic linguistics, the third indiana meeting 2012, vol. 59 (Michigan Slavic Materials), 176-189. Ann Arbor: Michigan Slavic Publications.

Merchant, Jason. 1999. The syntax of silence - sluicing, islands, and identity of ellipsis. UCSC Ph.D. dissertation.

Merchant, Jason. 2001. The syntax of silence: sluicing, islands, and the theory of ellipsis. 0xford: Oxford University Press.

Merchant, Jason. 2008. An asymmetry in voice mismatches in vp-ellipsis and pseudogapping. Linguistic Inquiry 39(1). 169-179.

Merchant, Jason. to appear. Ellipsis: a survey of analytical approaches. In Jeroen van Craenenbroeck, and Tanja Temmerman (eds.), The Oxford handbook of ellipsis. Oxford: Oxford University Press.

Merchant, Jason, and Andrew Simpson (eds.). 2012. Sluicing: cross-linguistic perspectives. Vol. 38 (Oxford Studies in Theoretical Linguistics). Oxford: Oxford University Press.

Nevins, Andrew Ira. 2010. Two case studies in phonological universals: a view from artificial grammars. Biolinguistics 4(4). 217-232.

Nishigauchi, Taisuke. 1998. 'Multiple sluicing' in Japanese and the functional nature of whphrases. Journal of East Asian Linguistics 7(2). 121-152.

Perfors, Amy, J Tenenbaum, and T Regier. 2011. Poverty of the stimulus: a rational approach. Cognition 118. 306-338.

Pullum, G.K., and B.C. Scholz. 2002. Empirical assessment of stimulus poverty arguments. The Linguistic Review 18(1-2). 9-50.

Reali, Florencia, and Morten H. Christiansen. 2005. Uncovering the richness of the stimulus: structure dependence and indirect statistical evidence. Cognitive Science 29. 1007-1028.

Rodrigues, Cilene, Andrew Ira Nevins, and Luis Vicente. 2009. Cleaving the interactions between sluicing and preposition stranding. In L. Wetzels, and Jeroen van der Weijer (eds.), Romance languages and linguistic theory 2006: selected papers from "Going romance", Amsterdam, 7-9 December 2006, 175-198. John Benjamins.

Ross, John Robert. 1969. Guess who? In Robert I. Binnick et al. (eds.), Papers from the fifth regional meeting of the chicago linguistic society, 252-286. Chicago: Chicago Linguistic Society, University of Chicago.

Sag, Ivan A. 1976. Deletion and logical form. MIT Doctoral dissertation.

Scatton, Ernest A. 1993. Bulgarian. In Bernard Comrie, and Greville G. Corbett (eds.), The Slavonic languages (Routledge Language Family Descriptions), 188-248. London \& New York: Routledge.

Takahashi, Daiko. 1994. Sluicing in japanese. Journal of East Asian Linguistics 3(3). 265-300.

Winkler, Susanne. 2013. Syntactic diagnostics for extraction of focus from ellipsis site. In Lisa Lai-Shen Cheng, and Norbert Corver (eds.), Diagnosing syntax (Oxford Studies in Theoretical Linguistics), chap. 23, 463-484. Oxford: Oxford University Press. 